\title{
miR-762 activation confers acquired resistance to gefitinib in non-small cell lung cancer
}

\author{
Peng Ge', Lei $\mathrm{Cao}^{2}$, Xin Chen ${ }^{1}$, Ruijun Jing ${ }^{1}$ and Wanxia Yue ${ }^{3 *}$
}

\begin{abstract}
Background: Epidermal growth factor receptor (EGFR)-tyrosine kinase inhibitors (TKIs) (e.g. gefitinib) currently remain the first-line treatment for patients with advanced non-small-cell lung cancer (NSCLC) with activating EGFR mutation. However, acquired resistance to gefitinib, which occurs frequently through unidentified mechanisms, significantly attenuate therapeutic effectiveness. Previous miRNA microarray analysis reveals that expression levels of a conserved oncomiR miR-762 are significantly upregulated in gefitinib-resistant NSCLC cells. We therefore aim to elucidate the role and underlying mechanisms of miR-762 during the pathogenesis of gefitinib resistance.

Methods: miR-762 expression in gefitinib-resistant NSCLC tissues and cells was evaluated using RT-qPCR. The potential regulation of miR-762 expression by IL-6 was studied using pharmacological and biochemical approaches. Effects of miR-762 manipulation on sensitivity to gefitinib was assessed using MTT, apoptotic ELISA and xenograft model. Finally, the posttranscriptional regulation of active BCR related protein (ABR) by miR-762 was determined using luciferase assay and site-directed mutagenesis.
\end{abstract}

Results: miR-762 expression was upregulated in gefitinib-resistant NSCLC tissues and cells, and this upregulation predicted a poor post-chemotherapy prognosis in NSCLC patients. miR-762 upregulation, induced by IL-6 signaling, significantly enhanced cell survival and rendered NSCLC cells unresponsiveness to gefitinib-elicited cell death. We finally provided the evidence that the oncogenic effect of miR-762 was mediated mainly through posttranscriptional repression of ABR in gefitinib-resistant NSCLC cells.

Conclusions: Our findings provide a rationale for future efforts testing miR-762 inhibition and ABR restoration COtreatment in patients with recurrent EGFR mutant NSCLC to therapeutically combat the heterogeneity of EGFR-TKIs resistance mechanisms.

Keywords: Non-small-cell lung cancer (NSCLC), Gefitinib resistance, miR-762, IL-6, ABR

\section{Background}

Currently, lung cancer (LC) represents one of the most aggressive cancer types with highest mortality in both developing and developed countries. Given that the constitutive activation of epidermal growth factor receptor (EGFR) signaling pathway plays an essential role in the development and progression of advanced non-small cell lung cancer (NSCLC) whose tumors harbor EGFRactivating mutations [1], EGFR-tyrosine kinase inhibitors

\footnotetext{
* Correspondence: xy2fyblk@163.com

${ }^{3}$ Department of Pathology, Second Affiliated Hospital of Xi'an Medical University, No.167 Fangdong Avenue, Baqiao District, Xi'an 710038, Shaanxi Province, People's Republic of China

Full list of author information is available at the end of the article
}

(TKIs) including gefitinib, erlotinib and afatinib, have become the standard of treatment for mutation-positive, advanced-stage non-squamous NSCLC [2]. Regardless of the certain improvement in clinical outcomes driven by EGFR-TKIs, however, frequent occurrence of acquired resistance to EGFR-TKIs significantly impedes therapeutic effectiveness and potentiates unfavorable prognosis in patients with EGFR-mutant NSCLC. Considering that neoadjuvant chemoradiotherapy has limited therapeutic effects and current prediction of disease prognosis still depends on conventional pathologic variables (tumor grade and metastasis status), there is an unequivocal need for elucidating the molecular underpinnings of NSCLC to develop more

(C) The Author(s). 2019 Open Access This article is distributed under the terms of the Creative Commons Attribution 4.0 International License (http://creativecommons.org/licenses/by/4.0/), which permits unrestricted use, distribution, and 
potent diagnostic biomarkers and therapeutic strategies, especially during the pathogenesis of EGFR-TKIs resistance.

MicroRNAs (miRNAs), a class of small, well-conserved, non-coding RNAs regulating a vast array of cellular processes by targeting the three prime untranslated region (3'-UTR) of target gene, are emerging as the largest contributors to the diversity of cellular functions under both physiological and pathological conditions. Recent profiling and functional studies have demonstrated that a panel of miRNAs (miR-608, - 4513, - 497, -499a [3], -23a [4] and et al.) are aberrantly expressed in EGFR-TKIs-resistant NSCLC, and dysregulation of these miRNAs regulates fundamentally the pathogenesis of EGFR-TKIs resistance via modulation of multiple cancerous functions including deregulated cell proliferation/apoptosis, maintenance of cancer stem cells and activation of alternative signaling (HGF, Met, AXL and IGF-1R). Of particular interest, a very recent study using high-throughput analysis (miRNA microarray analysis) demonstrates that miR-762 is significantly induced in experimentally established gefitinibresistant NSCLC cells. More importantly, silencing IGF-1R expression in gefitinib-resistant NSCLC cells totally abolishes miR-762 induction, suggesting a close connection between miR-762 expression and IGF-1R signaling pathway [5]. miR-762 has been shown to be a novel prognostic biomarker for muscle-invasive bladder cancer and ovarian cancer [6, 7]. Nevertheless, the function of miR-762 (either as oncomiR or tumor suppressor miRNA) and its corresponding mechanisms in gefitinib resistance remain poorly understood.

Acting as one of the most important EGFR bypass signaling pathways, IGF-1R signaling has been demonstrated to regulate essentially the EGFR-TKIs resistance in NSCLC $[5,8]$, the current study was designed to elucidate whether changes in miR-762 expression levels correlate to the development of resistance to gefitinib, and to further identify the putative targets of miR-762 using in vitro cell-based systems. Our profiling and functional data help us to propose that miR-762 acts as an oncomiR, whose expression is gradually upregulated along the development of gefitinib resistance, presenting a potential therapeutic vulnerability node for exploitation in the NSCLC treatment.

\section{Methods}

\section{Cell treatment}

Human NSCLC cell lines, including A549 (cat. No.: ATCC-CCL-185), NCI-H820 (cat. No.: ATCC-HTB-181), NCI-H2170 (cat. No.: ATCC-CRL-5928), NCI-H1650 (cat. No.: ATCC-CRL-5883), NCI-H1993 (cat. No.: ATCC-CRL-5909), NCI-H2126 (cat. No.: ATCC-CCL256), NCI-H1975 (cat. No.: ATCC-CRL-5908), NCIH1299 (cat. No.: ATCC-CRL-5803), NCI-H1648 (cat. No.: ATCC-CRL-5882), NCI-H1703 (cat. No.: ATCC-CRL-
5889), NCI-H2347 (cat. No.: ATCC-CRL-5942) and a normal human lung epithelial cell line NuLi-1 (cat. No.: ATCC-CRL-4011) were obtained from ATCC (Manassas, VA, USA) during the year 2018. Another NSCLC cell line PC-9 (cat. No.: RRID-CVCL-B260) was obtained from the State Key Laboratory (SKL) of Oncology in South China during the year 2018. All cell lines were recently authenticated by STR profiles with ABI3500xl Genetic Analyzer, and all cells were recently verified no contamination with mycoplasma before experiments. Cells were cultured in RPMI1640 medium containing 10\% fetal bovine serum (Thermo Fisher Scientific, Shanghai, China) at $37^{\circ} \mathrm{C}$ in a $5 \%-\mathrm{CO}_{2}$ incubator. Establishment of gefitinib-resistant NSCLC cells was achieved by incubating cells to gradually increasing concentrations of gefitinib (Sigma-Aldrich) for $\sim 11$ months (The maximum gefitinib concentrations were 5 and $40 \mu \mathrm{M}$ for PC-9/GR and A549/GR, respectively). The gefitinib-resistant sublines PC-9/GR and A549/GR were finally maintained in medium containing 5 or $40 \mu \mathrm{M}$ of gefitinib, respectively $[9,10]$. To study the potential regulation of miR-762 by various proinflammatory cytokines, A549 cells were incubated with different cytokines, including IL- $1 \alpha(5 \mathrm{ng} / \mathrm{ml}$,$) , IL- 1 \beta(10 \mathrm{ng} / \mathrm{ml}$,$) ,$ IL-6 $(10 \mathrm{ng} / \mathrm{ml}$,$) and IL-8 (50 \mathrm{ng} / \mathrm{ml}$,$) , for 24 \mathrm{~h}$. All these recombinant human cytokines were purchased from PeproTech (Suzhou, Jiangsu Province, China). To study the potential effects of IL-6 stimulation on miR-762 expression, cells were stimulated either with $10 \mathrm{ng} / \mathrm{ml}$ of IL-6 for different durations, or stimulated with different doses of IL- 6 for $24 \mathrm{~h}$. To investigate the STAT3-dependent regulation of miR-762 by IL-6, cells were stimulated with $10 \mathrm{ng} / \mathrm{ml}$ of IL- 6 for $24 \mathrm{~h}$, in the presence or absence or $5 \mu \mathrm{M}$ of WP1066 (Selleck, Shanghai, China). To further validate the STAT3dependent regulation of miR-762 by IL-6, A549 cells were transiently transfected with STAT3 siRNA or Ctrl siRNA (Santa Cruz Biotechnology, Shanghai, China) using Lipofectamine 2000 (Thermo Fisher Scientific) for $48 \mathrm{~h}$. The specificity and effectiveness of the STAT3 siRNA has been validated [11]. To manipulate the expression levels of miR762, NSCLC cells were transfected for $48 \mathrm{~h}$ with miR-762 inhibitors/mimics, along with the corresponding negative controls (NC) (Thermo Fisher Scientific, Shanghai, China), using Lipofectamine $2000[12,13]$. To generate the PC-9 or A549 cells stably expressing the exogenous active BCR related gene (ABR), cells were transfected with pCMV3-ABR or empty vector (Sinobiological, Beijing,China) for $48 \mathrm{~h}$, followed by selection with $200 \mu \mathrm{g} / \mathrm{ml}$ of hygromycin (Thermo Fisher Scientific).

\section{Cytotoxicity upon gefitinib challenge}

$48 \mathrm{~h}$ after transfection, LC cells were seeded at the density of $0.4 \times 10^{4}$ cells/well in a 96-well plate. Cells were then treated with different doses of gefitinib $(8 \mu \mathrm{M}$ for PC-9/ 
GR, $60 \mu \mathrm{M}$ for A549/GR, $0.2 \mu \mathrm{M}$ for PC-9 and $12.5 \mu \mathrm{M}$ for A549 cells) for 24 or $48 \mathrm{~h}$. Cell viability and apoptosis were assayed using a MTT Assay Kit (Abcam, Shanghai, China) and the ApoStrand ${ }^{\text {tix }}$ ELISA Apoptosis Detection Kit (ENZO LIFE, Farmingdale, NY, USA) at 590 and 405 $\mathrm{nm}$, respectively. The relative cell viability (\%) was expressed as a percentage of viable cell proportion for treated sample compared to that of mock control at $0 \mathrm{~h}$.

\section{In vivo chemosensitivity}

In vivo gefitinib sensitivity was evaluated using a xenograft model [3]. Briefly, LC cells were resuspended in culture medium and injected subcutaneously into the flanks of 6-week-old male BALB/c nude mice at the concentration of $1.0 \times 10^{6}$ cells $/ 200 \mu$ l of medium $(n=7 /$ group). When xenografts grew to $\sim 50 \mathrm{~mm}^{3}$, mice were administrated orally with gefitinib $[10 \mathrm{mg} / \mathrm{kg}$, dissolved in a volume of $150 \mu \mathrm{l}$ of vehicle control (Tween 80ethanol- $\left.\left.\mathrm{H}_{2} \mathrm{O}, 1: 1: 98\right)\right]$ on a daily basis. The control mice received the same volume of vehicle control. Tumor volume was measured once a week, using the formula: $\mathrm{V}$ $\left(\mathrm{mm}^{3}\right)=$ length $\times$ width ${ }^{2} \times 0.5$. At the end of 32 days after cell inoculation, mice were euthanized by carbon dioxide inhalation followed by cervical dislocation. The BALB/c nude mice were obtained from animal facility in Second Affiliated Hospital of Xi'an Medical University. All procedures involved in the animal work were strictly conformed to the Guide for the Care and Use of Laboratory Animals from NIH, and were approved by IACUCs of Second Affiliated Hospital of Xi'an Medical University (\#XAMU-2007-134-1A).

\section{Quantitative RT-PCR (RT-qPCR)}

Total RNA was isolated and purified using the mirVana ${ }^{\mathrm{Tm}}$ miRNA Isolation Kit (Thermo Fisher Scientific). Subsequent reverse transcription (RT) was conducted using the Applied Biosystems TaqMan MicroRNA Reverse Transcription Kit (Thermo Fisher Scientific). To detect miRNA expression, qPCR was conducted with the aid of the Applied Biosystems TaqMan MicroRNA Assays, using U6 expression for normalization. To detect other target transcripts, qPCR was performed using the SYBR Green Master Mix (Bio-Rad, Shanghai, China), as described earlier [14]. Amplification of ACTIN was served as the internal control. Relative expression levels were quantified using the the $2^{-\Delta C t}$ method [15]. The primers used were: ABR, 5'-AGCCGAGATATGAGCCTGAA-3' and 5'-CCTCGATACCCCTCTTCTCC-3' [16]; ACTIN, 5'-AGCACAATGAAGATCAAGAT-3' and 5' -TGTAAC GCAACTAAGTCATA-3' [3]; IL-1A, 5'-AACCAGTGCT GCTGAAGGA-3' and 5'-TTCTTAGTGCCGTG AGTTTCC-3'; $\quad I L-1 B, \quad 5^{\prime}$-CTGTCCTGCGTGTT GAAAGA-3' and 5' ${ }^{\prime}$-TTGGGTAATTTTTGGGAT CTACA-3'; IL-6, 5' -TTCAATGAGGAGACTTGCCTG-3' and $5^{\prime}$-ACAACAACAATCTGAGGTGCC-3' and $I L-8,5^{\prime}$ ACTCCAAACCTTTCCACCC-3' and 5'-AAACTTCTCC ACAACCTCTG-3' [17].

\section{Immunoblotting}

Total protein was prepared using the Total Protein Extraction Kit (Merck Limited, Hong Kong, China). Protein samples $(\sim 25 \mu \mathrm{g})$ were separated by SDS-PAGE and transferred to a PVDF membrane (Sigma-Aldrich). Membranes were then incubated with different primary antibodies (Additional file 4: Table S1) at $4{ }^{\circ} \mathrm{C}$ overnight, followed by incubation with an HRP-conjugated secondary antibody (Vector Laboratories, Burlingame, CA,USA) at rt. for $2 \mathrm{~h}$. Final immunobands were visualized with the assistance of a Pierce SuperSignal Kit (Thermo Fisher Scientific).

\section{Luciferase reporter assay}

We amplified the full-length 3'UTR of human $A B R$ gene from cDNA synthesized from total RNA of A549 cells using a GeneRacer Kit (Thermo Fisher Scientific), and cloned it into pGL3-Basic Vector using In-Fusion ${ }^{\circ} \mathrm{HD}$ Cloning Kit (Takara, Beijing, China). The site-directed mutagenesis was achieved with the aid of the QuikChange II site-directed mutagenesis kit (Agilent, Beijing, China). For reporter assay, we co-transfected miR-762 mimics/Mimics-NC (25 pmol/well) and pGL3-ABR 3'UTRLuc reporter $(0.25 \mu \mathrm{g} /$ well $)$, together with $0.001 \mu \mathrm{g}$ of the Renilla luciferase reporter (Promega, Beijing, China), into subconfluent proliferating NIH/3 T3 cells using Lipofectamine 2000 . $24 \mathrm{~h}$ later, cells were harvested and the relative luciferase (Luc) activity was measured using the DualLuciferase $^{\circ}$ Reporter $\left(\mathrm{DLR}^{\mathrm{m}}\right)$ System from Promega.

\section{Human samples}

Upon receipt of written informed consent from all participants, a total of 59 patients with recurrent EGFR mutant NSCLC who had been treated with epidermal growth factor receptor-tyrosine kinase inhibitors (EGFR-TKIs) were enrolled from Department of Cardiac \& Thoracic Surgery, Second Affiliated Hospital of Xi'an Medical University during the period from 2008 to 2016. Resistance to EGFR-TKIs was defined based on the criteria described elsewhere [18]. Tumor samples were obtained during rebiopsy. The human study was conducted in accordance with the Declaration of Helsinki (2013), and all the protocols involved were approved by the ethics committee review board at Second Affiliated Hospital of Xi'an Medical University (\#XAMU-2007-134-1B). The clinicopathologic features of the patients were presented in Table 1. 
Table 1 Pre-treatment characteristics of 59 patients with EGFR mutant NSCLC treated with first line EGFR-TKIs

\begin{tabular}{|c|c|}
\hline Clinical characteristics & Patient number (\%) \\
\hline \multicolumn{2}{|l|}{ Sex } \\
\hline Male & $36(61.0)$ \\
\hline Female & $23(39.0)$ \\
\hline \multicolumn{2}{|l|}{ Age } \\
\hline$<60$ & $40(67.8)$ \\
\hline$\geq 60$ & $19(32.2)$ \\
\hline \multicolumn{2}{|l|}{ Smoking status } \\
\hline Never smoked & $17(28.8)$ \\
\hline Former smoker & $28(47.5)$ \\
\hline Current smoker & $14(23.7)$ \\
\hline \multicolumn{2}{|c|}{ ECOG*performance status } \\
\hline 0 & $21(35.6)$ \\
\hline 1 & $32(54.2)$ \\
\hline 2 & $4(6.8)$ \\
\hline 3 & $2(3.4)$ \\
\hline \multicolumn{2}{|l|}{ Disease stage } \\
\hline$\| \mathrm{IIB}$ & $18(30.5)$ \\
\hline IV & $41(69.5)$ \\
\hline \multicolumn{2}{|l|}{ Brain metastasis } \\
\hline- & $51(86.4)$ \\
\hline+ & $8(13.6)$ \\
\hline \multicolumn{2}{|l|}{ Bone metastasis } \\
\hline- & $34(57.6)$ \\
\hline+ & $25(42.4)$ \\
\hline \multicolumn{2}{|l|}{ Type of EGFR mutation } \\
\hline Exon 19 deletion & $46(78.0)$ \\
\hline L858R & $12(20.3)$ \\
\hline Other & $1(1.7)$ \\
\hline \multicolumn{2}{|c|}{ EGFR-TKI type as first-line therapy } \\
\hline Gefitinib & $26(44.1)$ \\
\hline Erlotinib & $31(52.5)$ \\
\hline Afatinib & $2(3.4)$ \\
\hline
\end{tabular}

EGFR epidermal growth factor receptor, NSCLC non-small cell lung carcinoma, EGFR-TKIs epidermal growth factor receptor tyrosine kinase inhibitors, ECOG Eastern Cooperative Oncology Group

\section{Data analysis}

Data were analyzed using GraphPad Prism 5 from at least three independent experiments, and were expressed as mean \pm SD. Statistical comparisons were determined by either Student's $t$ test or one-way ANOVA, followed by Tukey post-hoc analyses wherever appropriate. The association between miR-762 and $A B R$ mRNA levels was assessed using the Pearson Chi-Square test and the survival difference was analyzed using Kaplan-Meier method. $P<0.05$ was considered statistically significant.

\section{Results}

\section{Upregulation of miR-762 is associated with gefitinib} resistance in NSCLC cells

To study the potential involvement of miR-762 in the regulation of chemosensitivity, we evaluated the expression profile of miR-762 in a bunch of NSCLC cells. Based on the IC50 values calculated from the MTT assays, we categorized the NSCLC cells into three groups: most sensitive to gefitinib (PC-9, NCI-H820 and NCI$\mathrm{H} 2170$, IC50 $\$ 5.0 \mu \mathrm{M})$, modestly sensitive to gefitinib (A549, NCI-H1650, NCI-H1993 and NCI-H2126, $5.0 \mu \mathrm{M}$ $\leqq \mathrm{IC} 50 \leqq 25.0 \mu \mathrm{M}$ ) and resistant to gefitinib (NCI-H1975, NCI-H1299, NCI-H1648, NCI-H1703 and NCI-H2347, IC50 $\geqq 25.0 \mu \mathrm{M}$ ) (Table 2). Subsequent RT-qPCR analyses revealed that miR-762 expression levels correlated negatively to the sensitivity to gefitinib in NSCLC cells, with the lowest values being observed in PC-9 cells and a normal human lung epithelial cell line (NuLi-1) and the highest values being detected in NCI-H2347 cells (Fig. 1a). We further chose PC-9 and A549 cells in our in vitro study, mainly based on three criteria: i) These two cell lines were shown to be relatively sensitive to gefitinib. ii) miR-762 expression is relatively low in these two cell lines. iii) These two cell lines are most commonly used NSCLC cells for the induction of gefitinib resistance [19]. Notably, miR-762 expression appeared to be irrelevant to the histological types in NSCLC cells (Fig. 1a, Table 2). To verify this observation, we generated the gefitinib-resistant sublines by exposing cells to gradually increasing concentrations of gefitinib. The resultant PC-9/GR and A549/GR cells exhibited more than 4.5-fold higher levels in gefitinib resistance, respectively (Fig. $1 \mathrm{~b}$ and c). Interestingly, miR-762 expression was significantly stimulated in gefitinib-resistant cells compared to their parental cells (Fig. 1d and e). These

Table 2 Sensitivity to gefitinib treatment for different NSCLC cells

\begin{tabular}{llll}
\hline Cell lines & Histology & EGFR mutation & IC50 of gefitinib $(\mu \mathrm{M})$ \\
\hline PC-9 & AD & E746-A750 del & $0.047 \pm 0.012$ \\
NCl-H820 & AD & E746-E749 del & $2.783 \pm 0.854$ \\
NCI-H2170 & SQ & WT & $4.254 \pm 0.752$ \\
A549 & AD & WT & $9.172 \pm 1.228$ \\
NCI-H1650 & AD & E746-A750 del & $10.473 \pm 2.164$ \\
NCl-H1993 & AD & WT & $16.432 \pm 0.965$ \\
NCl-H2126 & LC & WT & $23.179 \pm 2.843$ \\
NCI-H1975 & AD & L858R & $26.748 \pm 3.386$ \\
NCl-H1299 & LC & WT & $28.637 \pm 2.512$ \\
NCI-H1648 & AD & WT & $38.425 \pm 1.838$ \\
NCl-H1703 & SQ & WT & $41.258 \pm 5.217$ \\
NCI-H2347 & AD & WT & $62.417 \pm 4.658$
\end{tabular}

NSCLC non-small cell lung carcinoma, $A D$ adenocarcinoma, SQ squamous cell carcinoma, LC large cell carcinoma, WT wild type 

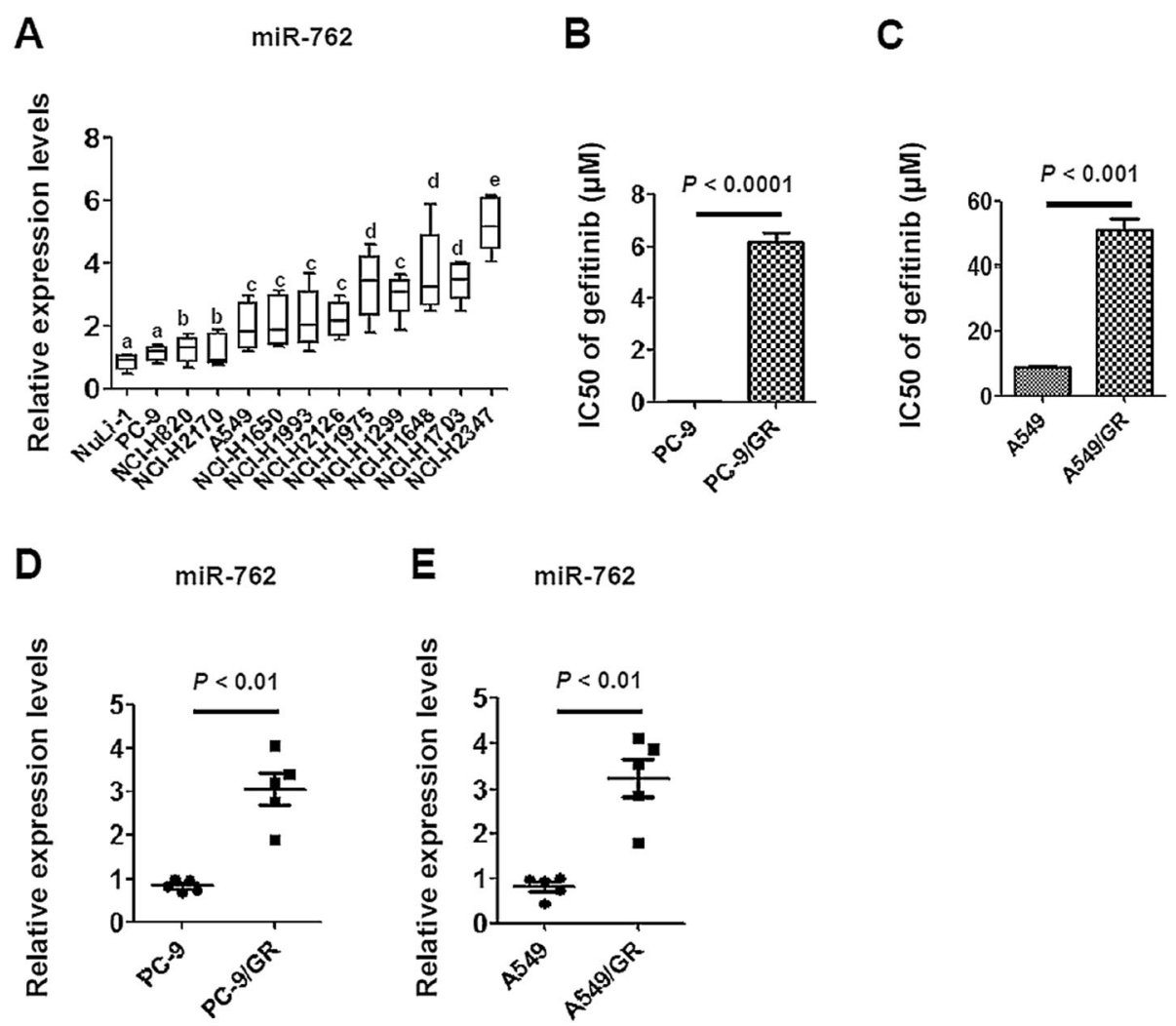

Fig. 1 Elevated miR-762 expression is associated with gefitinib resistance in NSCLC cells. a RT-qPCR analysis of miR-762 expression in different NSCLC cells. Relative expression levels of miR-762 were obtained in each sample by normalization of the expressions of miR-762 to that of the U6 snRNA signal. For presentation of data, expression levels of miR-762 from NuLi-1 cells were taken as 100\% and the others were normalized accordingly. Each value is a mean \pm S.E.M. from three independent experiments. Different superscript letters denote groups that are statistically different $(P<0.05)$. b The IC50 value (inhibitory concentration to produce $50 \%$ cell death) following a 48 -h exposure to gefitinib was determined in PC-9 and PC-9/GR cells using MTT assay. c The IC50 value following a 48-h exposure to gefitinib was determined in A549 and A549/GR cells using MTT assay. $\mathbf{d}$-e Characterization of miR-762 expression in different NSCLC cells using RT-qPCR. The value indicates the relative expression levels of miR-762 in the cells (PC-9/PC-9/GR and A549/A549/GR cells) at different batches of gefitinib resistant induction

findings suggest that miR-762 upregulation may be associated with the pathogenesis of gefitinib resistance in NSCLC cells.

\section{Potential regulation of miR-762 expression by the pro- inflammatory cytokine IL-6}

Because emerging data suggest that deregulated miR-762 expression is involved in immune regulation in different systems [20, 21], and because immune dysregulation represents one of the most important etiologies of gefitinib resistance in NSCLC [22], we therefore hypothesize that miR-762 actions on sensitivity to gefitinib may be exerted via modulation of immune response. In our ongoing study, we unexpectedly found that among different pro-inflammatory cytokines tested, expression levels of IL-6 transcripts were induced unanimously in both PC9/GR and A549/GR cells, compared to their parental cells (Fig. 2a-b). To be noted, IL-8 expression levels were observed to be increased in PC-9/GR cells compared to its parental PC-9 cells, but displayed no differential expression pattern in A549/GR and A549 cells (Fig. 2a). Considering that IL-8 signaling has been shown to be fundamentally involved in resistance of lung carcinoma cells to the EGFR TKI erlotinib [23], our results suggest that IL-8 action on response to EGFR TKIs may be dependent on cell context or types of TKIs-treatments. Despite the essential roles of miRNAs in human physiology and diseases, transcriptional regulation of miRNAs is so far poorly understood. To this end, emerging data have shown that certain inflammatory cytokines can function as potent regulators of miRNA expression. These cytokines and miRNAs form into a delicate regulatory network consisting of both feed forward and feedback loops, thus contributing crucially to cancerous progression [24]. The available data thus raise the possibility that miR-762 expression may be regulated by IL-6 signaling. Indeed, upon being challenged for $24 \mathrm{~h}$ with different recombinant human cytokines including IL- $1 \alpha$, IL-1 $\beta$, IL- 6 and IL-8, only IL-6 stimulated a significant elevation in miR-762 expression in A549 cells (Fig. 2c). 

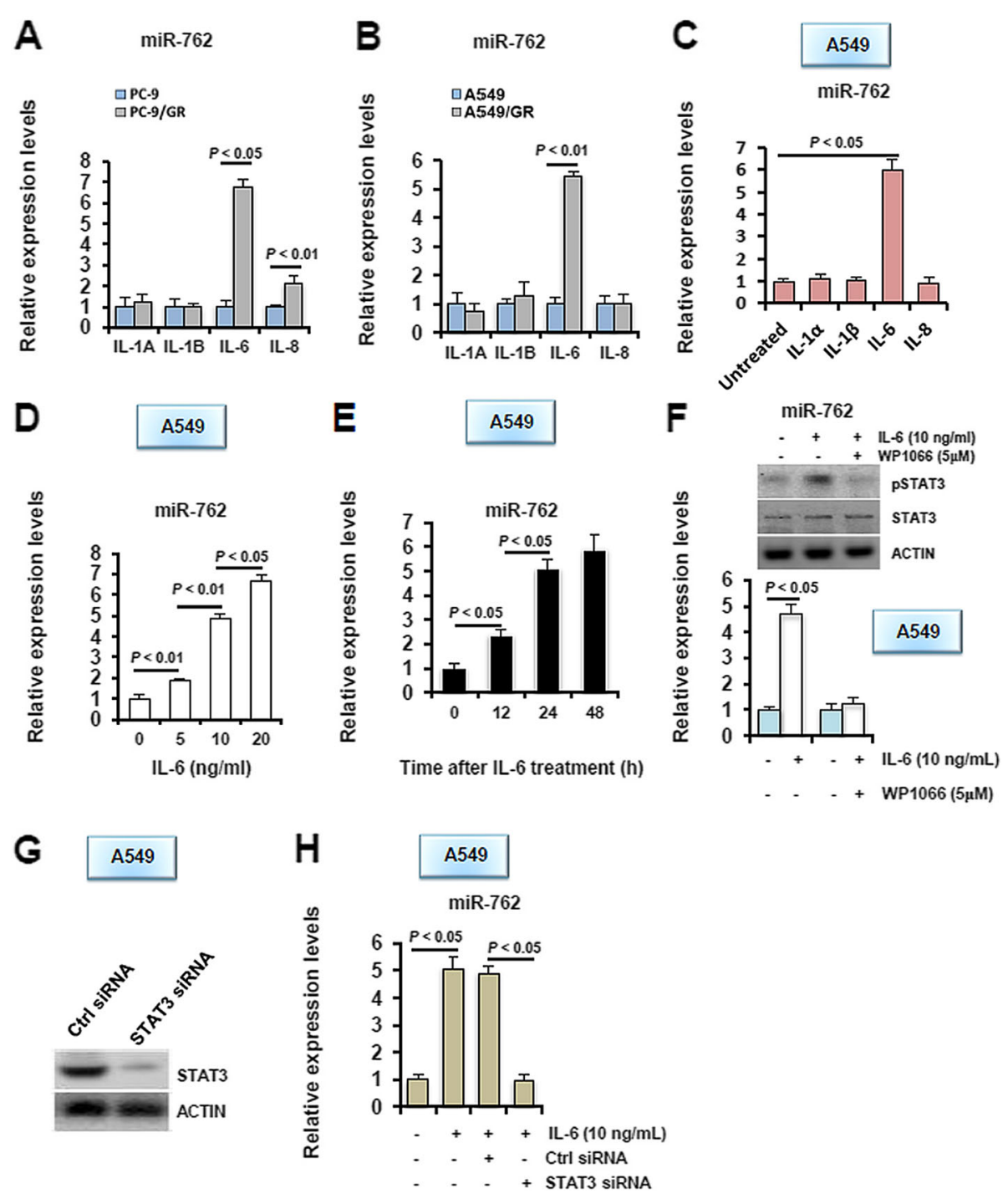

Fig. $\mathbf{2}$ IL-6 serves as a potential upstream regulator of miR-762 induction in NSCLC cells. a-b Characterization of expression levels of different cytokines in different NSCLC cells using RT-qPCR. Each value is a mean \pm S.E.M. from three independent experiments. c A549 cells were incubated with different cytokines, including IL-1a $(5 \mathrm{ng} / \mathrm{ml}), \mathrm{IL}-1 \beta(10 \mathrm{ng} / \mathrm{ml}), \mathrm{LL}-6(10 \mathrm{ng} / \mathrm{ml})$ and IL-8 $(50 \mathrm{ng} / \mathrm{ml})$ for $24 \mathrm{~h}$, followed by RT-qPCR analysis of miR-762 expression. $\mathbf{d}$ A549 cells were stimulated with different doses of IL-6 for $24 \mathrm{~h}$, followed by RT-qPCR analysis of miR-762 expression. e A549 cells were stimulated with $10 \mathrm{ng} / \mathrm{ml}$ of IL-6 for different durations as indicated, followed by RT-qPCR analysis of miR-762 expression. f A549 cells were stimulated with $10 \mathrm{ng} / \mathrm{ml}$ of IL-6, in the presence or absence or co-treatment with $5 \mu \mathrm{M}$ of WP1066, for $24 \mathrm{~h}$, followed by RT-qPCR analysis of miR-762 expression. Inhibition of STAT3 activation was verified using immunoblotting analysis of pSTAT3 expression (upper panel). $\mathbf{g}$ A549 cells were transiently transfected with STAT3 siRNA or Ctrl siRNA. $48 \mathrm{~h}$ later, knockdown of STAT3 in A549 cells was validated using immunoblotting. $\mathbf{h}$ $48 \mathrm{~h}$ after siRNA treatment, A549 cells were stimulated with $10 \mathrm{ng} / \mathrm{ml}$ of IL-6 for $24 \mathrm{~h}$, followed by RT-qPCR analysis of miR-762 expression

This stimulatory effect was later found to be exerted in a dosage-dependent (Fig. 2d) and time-dependent (Fig. 2e) manner. To further determine whether the regulation of miR-762 expression by IL-6 was mediated through STAT3 signaling, we treated A549 cells for $24 \mathrm{~h}$ with 10 $\mathrm{ng} / \mathrm{ml}$ of IL-6, in the presence or absence of the STAT3 inhibitor WP1066. Co-treatment with WP1066 concomitantly abolished IL-6-elicited pSTAT3 induction and miR-762 upregulation in A549 cells (Fig. 2f). To further validate this observation, we transiently knocked down the expression of endogenous STAT3 in A549 cells (Fig. 2), and then subjected these cells to IL-6 stimulation. Similarly as being treated by WP1066, ablation of STAT3 in A549 cells completely eliminated IL-6induced miR-762 elevation (Fig. 2h). Moreover, the potential regulation of miR-762 by the IL-6/STAT3 cascade has been also verified in PC-9 cells (Additional file 1: Figure S1). We have thus identified a potential regulation of miR-762 by the IL-6/STAT3 cascade in NSCLC cells. 
miR-762 regulates sensitivity to gefitinib in NSCLC cells Having established the association between miR-762 upregulation and impaired gefitinib chemosensitivity, we next explored the role of miR-762 in the modulation of gefitinib resistance by performing gain- and loss-offunction experiments. Transient transfection with miR762 inhibitors caused a $67.6 \%$ and a $58.1 \%$ reduction in the miR-762 levels in PC-9/GR and A549/GR cells relative to transfection with inhibitors negative control (inhibitors-NC), respectively (Fig. 3a). Ablation of endogenous miR-762 in PC-9/GR and A549/GR cells significantly impaired cell viability (Fig. $3 \mathrm{~b}$ ) and potentiated apoptosis (Fig. 3c) at 24 to $48 \mathrm{~h}$ following gefitinib exposure. In accordance with these in vitro results, miR762 inhibition in PC-9/GR and A549/GR cells noticeably suppressed tumor formation in the gefitinib-challenged xenograft model (Fig. 3d). To directly ask whether miR762 could promote gefitinib resistance, we transiently overexpressed miR-762 mimics in PC-9 and A549 cells (Fig. 3e). As expected, augmentation of miR-762 expression in PC-9 and A549 cells dramatically enhanced cell viability (Fig. 3f) and attenuated apoptosis (Fig. 3g) at 24 to $48 \mathrm{~h}$ following gefitinib exposure. Likewise, overexpression of the exogenous miR-762 notably promoted tumor formation in the gefitinib-challenged xenograft model (Fig. 3h). These data collectively suggest that miR-762 could regulate sensitivity to gefitinib at both in vitro and in vivo levels in NSCLC cells.

\section{miR-762 directly targets ABR signaling in NSCLC cells}

To dissect the molecular mechanisms underlying the aforementioned phenotype, we searched two public databases, namely Target scan and miRDB. 42 candidate genes were found to be potential targets of miR-762 by both programs (Fig. 4a, Additional file 5: Table S2). Among these candidate genes, we further chose to focus on active BCR related protein (ABR), mainly based on three reasons: i) We searched for potential targets of miR-762 based on those genes with oncogenic or apoptosis-regulating properties. To this end, ABR has been validated to be a potent tumor suppressor that plays an important role in chronic myeloid leukemia and meningiomas [25]. ii) Our in silico analysis revealed that 3'-UTR of human ABR contains a potential miR-762binding site (data not shown). iii) Our preliminary expression profile analysis revealed that levels of miR-762 expression were negatively correlated to $A B R$ mRNA levels in a 59-patient cohort (see below). The expression levels of miR-762 and endogenous $A B R$ mRNA appeared to be negatively correlated, as shown in Fig. 1d-e and Additional file 2: Figure S2. Importantly, transient expression of miR-762 inhibitors in PC-9/GR and A549/ GR cells significantly evoked the ABR expression at both protein (Fig. 4b) and mRNA (Fig. 4c) levels. In good contrast, upregulation of miR-762 expression by transient overexpression of miR-762 mimics effectively repressed the ABR expression in gefitinib-sensitive PC-9 and A549 cells (Fig. 4d and e). To directly assay the transcriptional regulation of $A B R$ expression by miR762, we employed a luciferase reporter assay. Cotransfection with miR-762 mimics and WT-pGL3-ABR 3'UTR-Luc reporter plasmids for $24 \mathrm{~h}$ in subconfluent proliferating NIH/3 T3 cells resulted in a $71.4 \%$ reduction in the $A B R$ mRNA levels. This inhibitory effect was totally abolished when WT-pGL3-ABR 3'UTR-Luc reporter plasmids were replaced by $\mathrm{Mu}-\mathrm{pGL3}-\mathrm{ABR}$ 3'UTR-Luc reporter plasmids in the luciferase reporter assay (Fig. 4f). miR-762 thus represses the ABR expression by decreasing its mRNA stability in NSCLC cells.

\section{Ectopic expression of the exogenous $A B R$ ameliorates miR-762-impaired gefitinib sensitivity in NSCLC cells}

To further authenticate the involvement of ABR signaling in miR-762-impaired gefitinib sensitivity, we generated the PC-9 and A549 cells that stably expressed exogenous ABR. As shown by immunoblotting analyses, ABR expression was successfully restored in PC-9/ABR and A549/ ABR cells, even in the presence of miR-762 mimics (Fig. 5a). Upon gefitinib challenge, transient transfection with miR-762 mimics caused a significant increase in cell viability in PC-9 and A549 cells, and this stimulatory effect was substantially abolished in PC-9/ABR and A549/ABR cells (Fig. 5b). Consistently, miR-762 mimics-repressed cell apoptosis in gefitinib-exposed LC cells was effectively restored by ABR overexpression (Fig. 5c). Moreover, transfection with miR-762 mimics in PC-9 and A549 cells notably promoted gefitinib resistance and increased tumor formation in a xenograft model. This stimulatory effect of miR-762 mimics was observed to be effectively reversed by $A B R$ overexpression (Mimics + gefitinib + vector v.s. Mimics + gefitinib + pCMV-ABR, Fig. 5d). Thus, we have provided the evidence that the promoting effect of miR762 mimics on gefitinib resistance in NSCLC cells is mediated mainly through the dysregulation of ABR pathway.

\section{Translational significance of deregulated miR-762 expression in EGFR-TKIs resistance in NSCLC}

We finally determined the clinical relevance of the current study by investigating the miR-762 expression status in a cohort of 59 patients with recurrent EGFR mutant NSCLC after the EGFR-TKIs therapy. miR-762 levels were significantly induced in EGFR-TKIs nonresponding tissues relative to responding tissues $(2.64 \pm$ 0.97 v.s. $1.17 \pm 0.84, P<0.01$, Fig. 6a). Furthermore, miR762 expression was found to be negatively correlated to $A B R$ mRNA levels in our cohort of 59 NSCLC patients who had previously received EGFR-TKIs treatment ( $r=$ $-0.7294, P<0.0001$, Fig. $6 b)$. To further validate the 

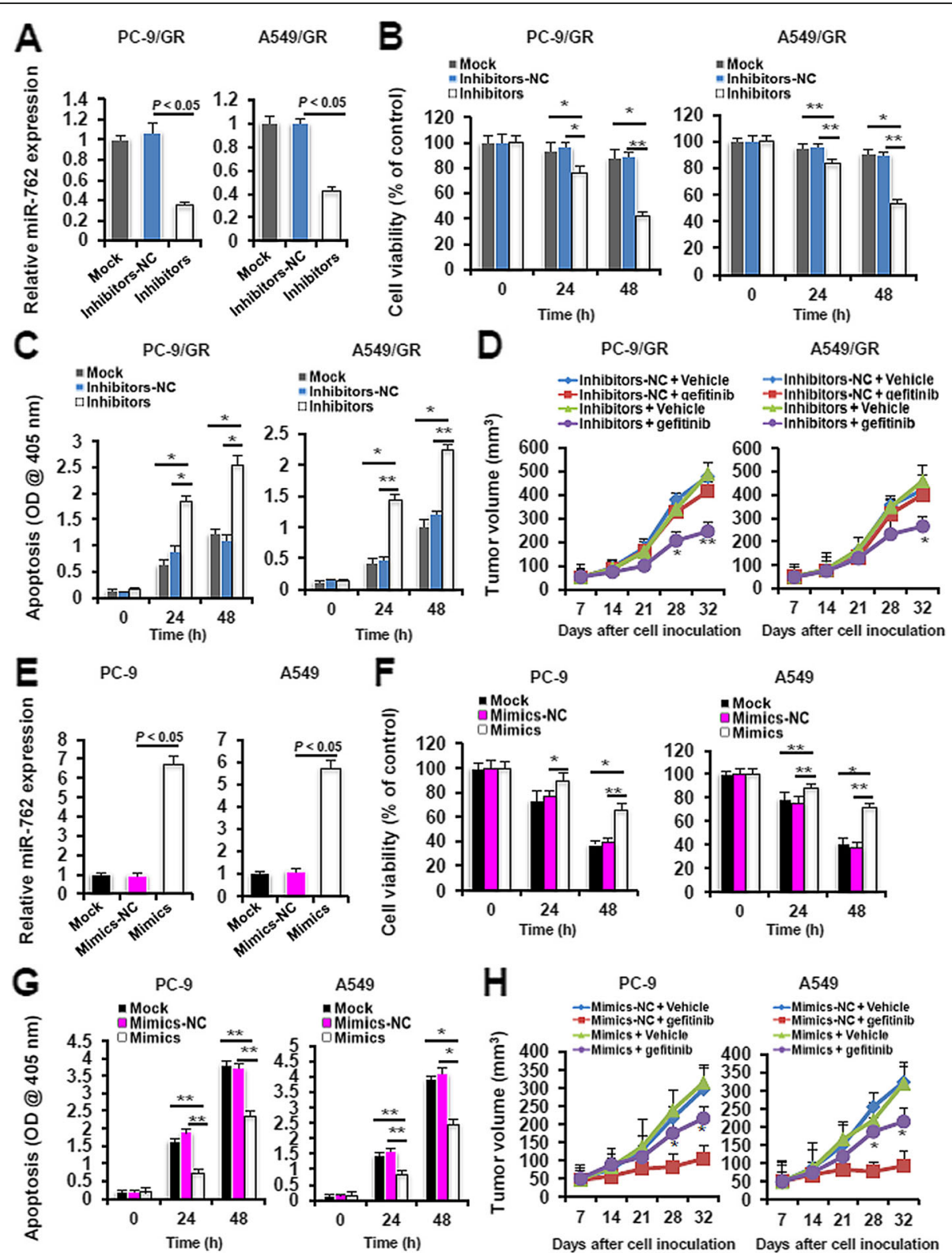

Fig. 3 miR-762 upregulation desensitizes NSCLC cells to gefitinib treatment. a $48 \mathrm{~h}$ after transfection with miR-762 inhibitors or negative controls (NC), PC-9/GR and A549/GR cells were subjected to RT-qPCR analysis of miR-762 expression. b PC-9/GR and A549/GR cells were treated with different doses of gefitinib ( $8 \mu \mathrm{M}$ for PC-9/GR, $60 \mu \mathrm{M}$ for A549/GR) for 24 or $48 \mathrm{~h}$. Cell viability was assayed using a MTT Assay Kit at $590 \mathrm{~nm}\left({ }^{*} P<\right.$ 0.05 and $\left.{ }^{* *} P<0.01\right)$. c Cells were treated with different doses of gefitinib $(8 \mu \mathrm{M}$ for PC-9/GR, $60 \mu \mathrm{M}$ for A549/GR) for 24 or $48 \mathrm{~h}$. Cell apoptosis was assayed using an ApoStrand ${ }^{T M}$ ELISA Apoptosis Detection Kit at $405 \mathrm{~nm}\left({ }^{*} P<0.05\right.$ and $\left.{ }^{* *} P<0.01\right)$. d In vivo gefitinib sensitivity was evaluated using a xenograft model, as described in Materials and methods. Tumor volume was measured and recorded once a week ${ }^{*} P<0.05$ and ${ }^{* *} P<$ 0.01 when comparing Inhibitors + vehicle to Inhibitors + gefitinib). e $48 \mathrm{~h}$ after transfection with miR-762 mimics or Mimics-NC, PC-9 and A549 cells were subjected to RT-qPCR analysis of miR-762 expression. f PC-9 and A549 cells were treated with different doses of gefitinib $(0.2 \mu \mathrm{M}$ for PC-9 and $12.5 \mu \mathrm{M}$ for A549 cells) for 24 or $48 \mathrm{~h}$. Cell viability was assayed using a MTT Assay Kit at $590 \mathrm{~nm}\left({ }^{*} P<0.05\right.$ and $\left.{ }^{* *} P<0.01\right)$. g PC-9 and A549 cells were treated with different doses of gefitinib $(0.2 \mu \mathrm{M}$ for PC-9 and $12.5 \mu \mathrm{M}$ for A549 cells) for 24 or $48 \mathrm{~h}$. Cell apoptosis was assayed using an ApoStrand $d^{T M}$ ELISA Apoptosis Detection Kit at $405 \mathrm{~nm}\left({ }^{*} P<0.05\right.$ and $\left.{ }^{*} P<0.01\right)$. $\mathbf{h}$ In vivo gefitinib sensitivity was evaluated using a xenograft model, as described in Materials and methods. Tumor volume was measured and recorded once a week $\left({ }^{*} P<0.05\right.$ and ${ }^{* *} P<0.01$ when comparing Mimics + vehicle to Mimics + gefitinib)

clinical importance of miR-762 expression, we divided the subgroups (high/low miR-762) according to the median value as a cutoff [26]. Interestingly, high levels of
miR-762 predisposed the NSCLC patients receiving EGFR-TKIs chemotherapy to a significantly shorter progression-free survival (Fig. 6c) and overall survival 


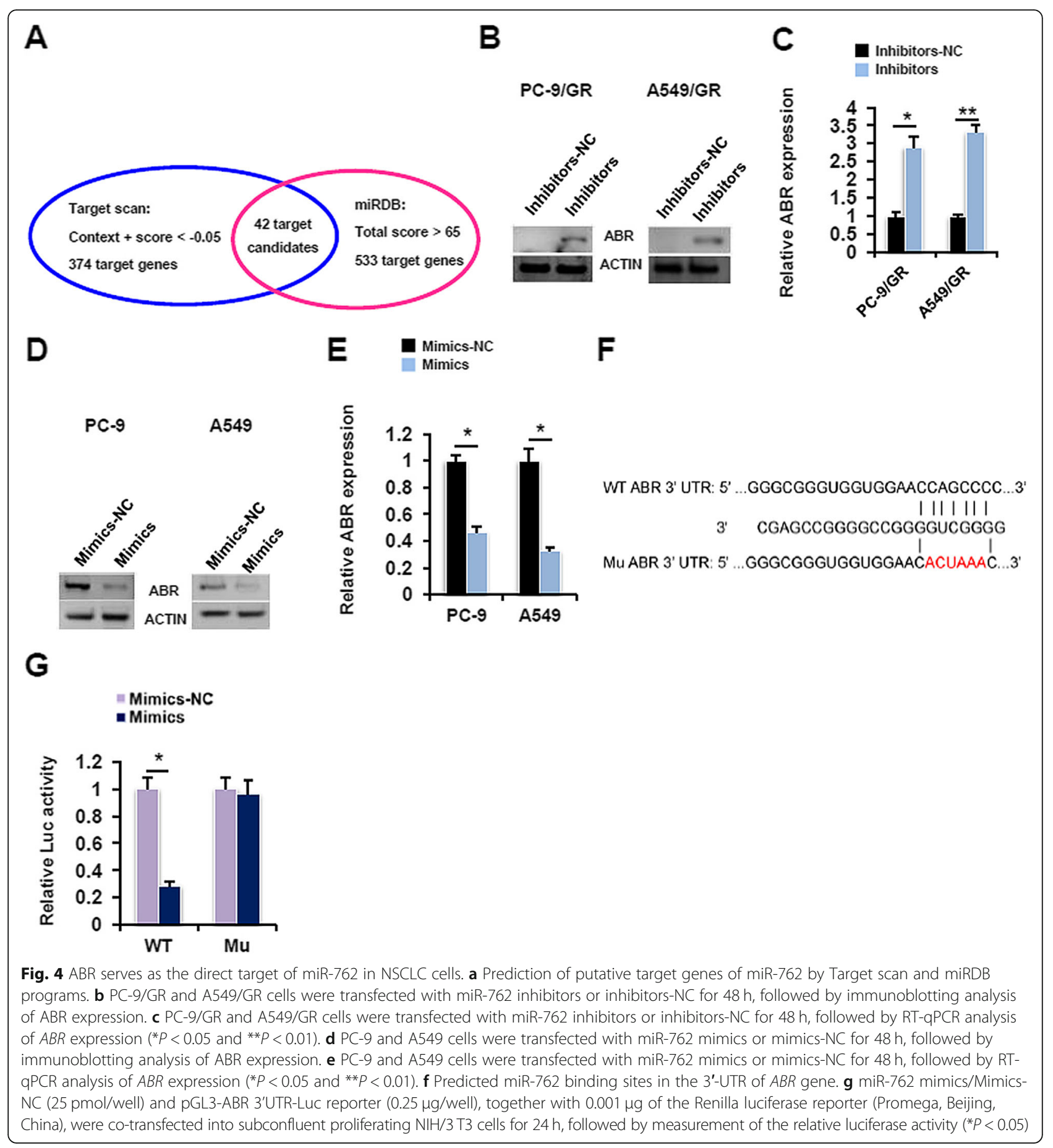

time (Fig. 6d). The available data thus point to a potent prognostic value of miR-762 in NSCLC patients after EGFR-TKIs therapy.

\section{Discussion}

Recent microarray and RNA-sequencing studies have identified a bunch of miRNAs expressed aberrantly in gefitinib-resistant NSCLC cells [27]. The function and underlying mechanisms of these differentially expressed
miRNAs, however, remain largely unknown. To this end, miR-762 was selected and subjected to further investigation based on three criteria: i) Misexpression of miR-762 during carcinogenesis and tumor progression has been reported previously by independent groups $[6,7,28]$. ii) Aberrant miR-762 expression has been shown in tumor samples and not just cell lines [28]. iii) Functional evidence of miR-762 as a conserved oncomiR in various tumor types has been presented by multiple publications 


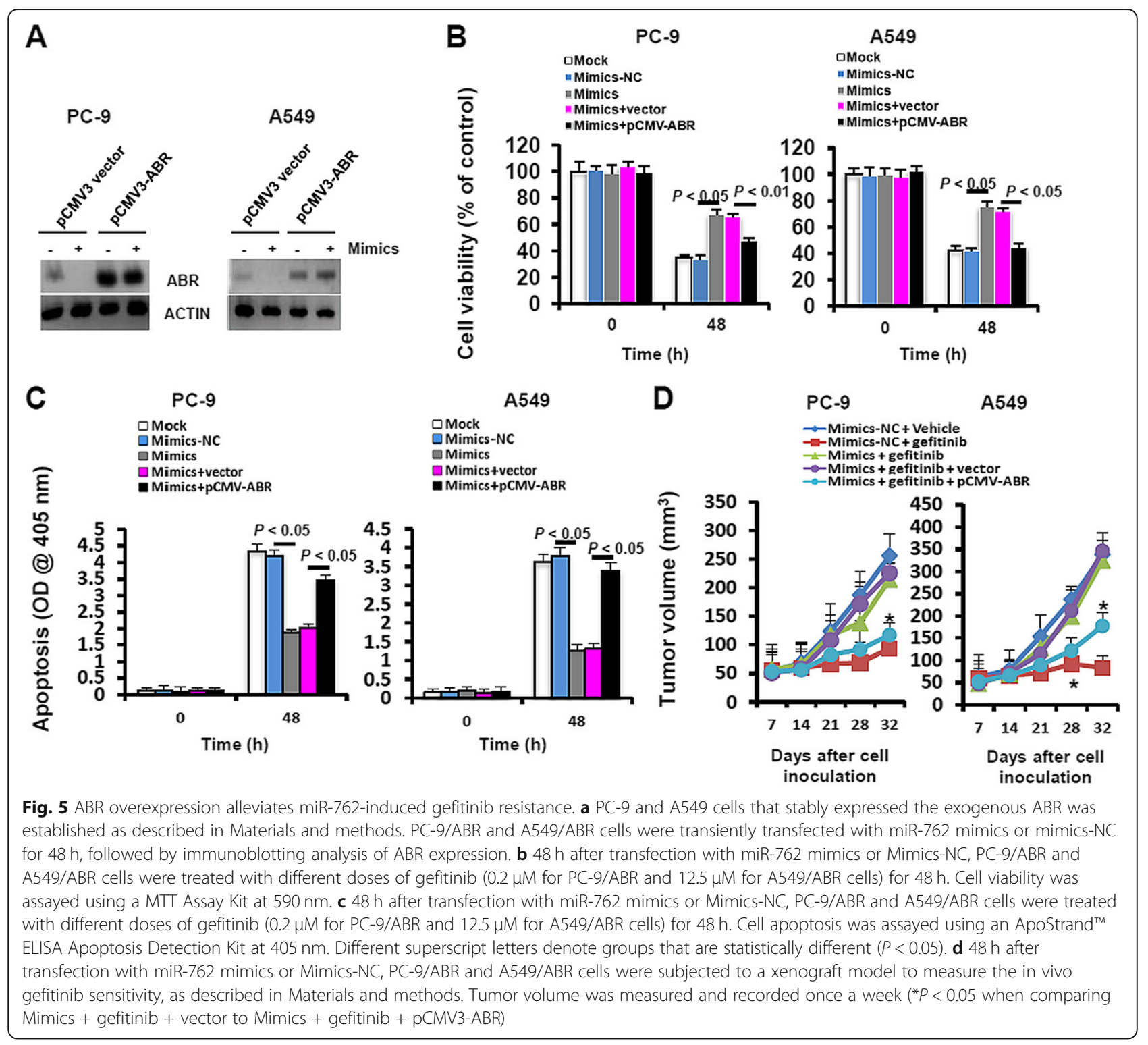

$[6,7,28]$. We observed that miR-762 expression was significantly increased in experimentally established gefitinib-resistant NSCLC cells compared to the parental cells. A stepwise increase in miR-762 expression was even more prominent in different NSCLC cells with low or moderate sensitivity to gefitinib (Fig. 1), suggesting a close association between miR-762 dysregulation and pathogenesis of gefitinib resistance in NSCLC.

Despite much efforts focused on the identification of the down-stream targets of miRNAs, very little is known on the regulation of miRNAs themselves. To this end, our profiling assays have revealed that IL- 6 may regulate miR-762 expression in NSCLC cells. This conclusion was drawn based upon three observations: i) IL-6 stimulated miR-762 expression in a dose- and time-dependent manner (Fig. 2c-e). ii) Blockage of the STAT3 activation using pharmacological or molecular biology approaches totally abrogated miR-762 upregulation in IL-6challenged NSCLC cells (Fig. 2f-h). iii) Emerging data suggest that expression of miRNAs is primarily regulated at the level of promoter transcription [29]. Interestingly, with the aid of the PROmiRNA database, we have identified a putative STAT3 binding site in the 5'-UTR of pre-miRNA of hsa-miR-762 (Additional file 3: Figure S3). Based on the available data, we conclude that miR762 expression may be regulated fundamentally by IL-6/ STAT3 cascade in NSCLC cells. Previous studies have shown that IL-6/STAT3 activation could attenuate sensitivity to EGFR-mutant NSCLC cells to EGFR-TKIs including icotinib [30] and gefitinib [31]. Our findings extend these understandings by identifying miR-762 as a potential downstream effector of IL-6/STAT3 pathway 


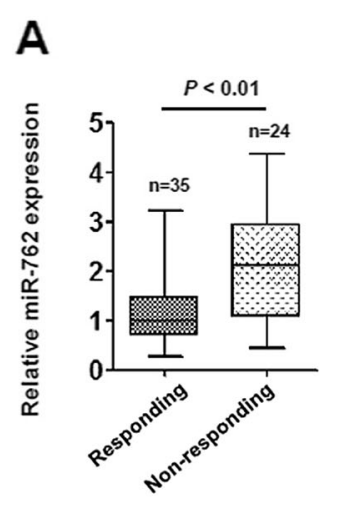

B

D

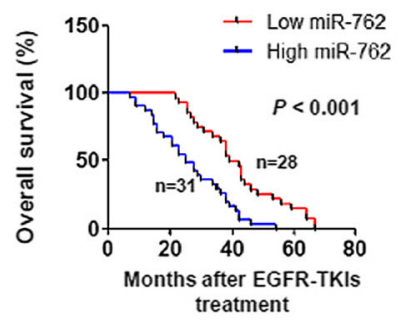

C
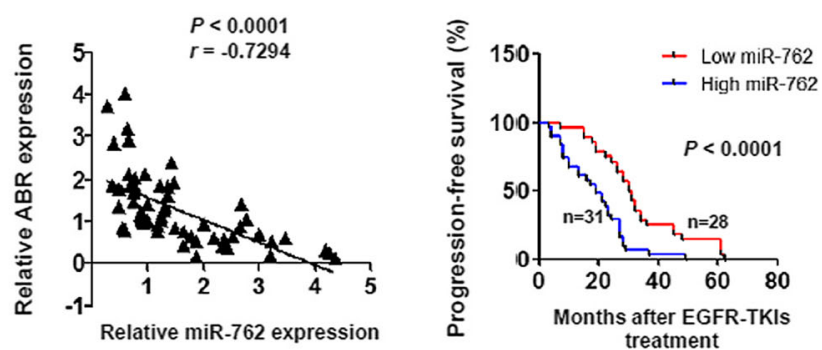

$\mathbf{E}$

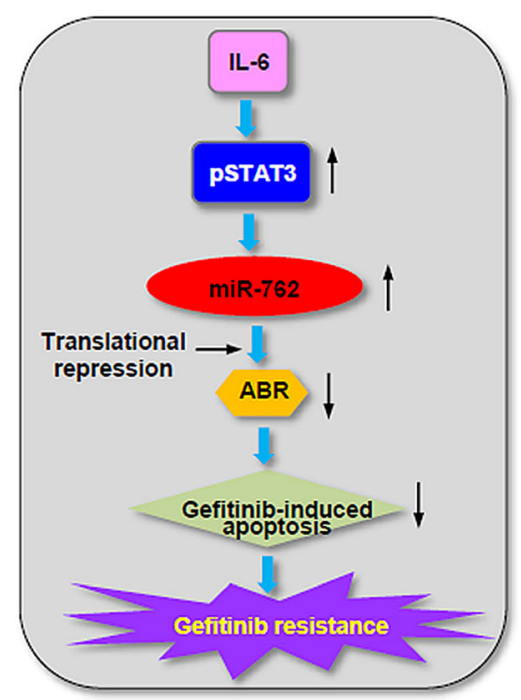

Fig. 6 Translational significance of deregulated miR-762 expression in EGFR-TKIs-treated NSCLC. a RT-qPCR analysis of miR-762 expression in human EGFR-TKls-responding, and EGFR-TKls-non-responding NSCLC biopsies. b Expression levels of miR-762 and ABR mRNA in a total 59 of NSCLC tissue samples were determined using RT-qPCR analysis, followed by Pearson Chi-Square test. c Progression-free survival according to baseline miR-762 expression for 59 patients with EGFR-mutant NSCLC treated with first-line EGFR-TKIs. (d) (c) Overall survival according to baseline miR-762 expression for 59 patients with EGFR-mutant NSCLC treated with first-line EGFR-TKIs. e Proposed working model in the current study

in EGFR-TKIs-resistant NSCLC cells. This intriguing possibility is currently being given a full investigation in our lab.

In the context of malignant behavior, miR-762 expression has been shown to be notably upregulated in muscle-invasive bladder cancer [6] and ovarian cancer [7], and this upregulation frequently predicts a poor prognosis of corresponding patients. In agreement with these findings, our gain- and loss-of-function approaches demonstrates that elevated miR-762 enhances multiple aspects of malignant phenotypes including cell proliferation, resistance to gefitinib-induced apoptosis, thus potentiating cancerous progression in NSCLC (Fig. 3). The available data indicate that the oncogenic function may be an intrinsic character of miR-762. Given that aberrant miR-762 expression can also be found in plasma of patients with muscle-invasive bladder cancer [6] and Graves' disease [32], future endeavor in this filed may help to screen an early, more convenient biomarker with potential diagnostic value.

By profiling NSCLC cells in the setting of ectopic miR-762 expression, we have identified $A B R$ as the potential downstream target, and we have confirmed the direct binding of miR-762 to the 3 '-UTR of $A B R$ using multiple approaches including transient transfection, luciferase reporter assay and site-directed mutagenesis (Fig. 4). $A B R$, a homologue of $B C R$ (breakpoint cluster region) gene, regulate a diversity of biological functions through negative modulation of the activation of the small GTPase Rac. Regarding the function/regulation of ABR, two fundamental aspects are worthy of note: i) ABR serves as a relatively conserved tumor suppressor in various solid tumors including medulloblastoma [33], breast cancer [34] and astrocytoma [35]. Nevertheless, whether ABR is subjected to transcriptional or posttranscriptional regulation remain unexplored. ii) Dysregulation 
of ABR function is associated with IL-6 activation. For example, in the absence of active ABR, hypoxia induces GTPbound form of Rac, thus causing enhanced production of IL-6 during the pathogenesis of pulmonary hypertension [36]. The data shown here indicate that miR-762 is required for ABR inhibition by IL-6 in NSCLC cells. It will be of future interest to deconvolute a miR-762/ABR/Rac axis is also at play in EGFR-TKIs-resistant NSCLC.

The importance of the miR-762/ABR signaling in EGFR-TKIs resistance was finally validated in clinical samples from EGFR-mutant NSCLC patients. miR-762 levels were found to be significantly increased in EGFRTKIs non-responding tissues relative to responding tissues. More importantly, high levels of miR-762 predisposed the NSCLC patients receiving EGFR-TKIs chemotherapy to a significantly shorter progression-free survival and overall survival time (Fig. 6). Of note, some patients harbor higher levels of miR-762 expression, and they also respond to gefitinib treatment properly (Fig. 6a). This is probably due to the fact that NSCLC is a heterogeneous set of cancer [37]. Anyway, our clinical data are based on a small size of NSCLC patients, and therefore have a certain limitation. A further study consisting of a larger scale of NSCLC patients is warranted thereof. Nevertheless, our clinical findings provide the first evidence for the potential usage of evaluating miR-762/ABR ratios as a molecular predictor of chemosensitivity to EGFR-TKIs in NSCLC.

\section{Conclusions}

The data presented here have demonstrated that miR762 upregulation, which is regulated, at least in part, by IL6/STAT3 signaling pathway, confers acquired resistance to gefitinib in NSCLC cells (Fig. 6e). From a clinical standpoint, miR-762 upregulation is tightly associated with the pathogenesis of gefitinib resistance, and may serve as a potent predictor of a poor response to EGFRTKIs in NSCLC patients. In this context, miR-762 inhibition using systemic delivery (e.g. nanoparticles) may represent an attractive therapeutic strategy for patents with recurrent EGFR mutant NSCLC.

\section{Supplementary information}

Supplementary information accompanies this paper at https://doi.org/10. 1186/s12885-019-6416-4.

\footnotetext{
Additional file 1: Figure $\mathbf{S 1}$. Verification of the regulation of miR-762 expression by IL-6 signaling pathway in PC-9 cells. (A) PC-9 cells were incubated with different cytokines, including IL-1a $(5 \mathrm{ng} / \mathrm{ml}), \mathrm{IL}-1 \beta$ $(10 \mathrm{ng} / \mathrm{ml}), \mathrm{IL}-6(10 \mathrm{ng} / \mathrm{ml})$ and IL-8 $(50 \mathrm{ng} / \mathrm{ml})$ for $24 \mathrm{~h}$, followed by RT-qPCR analysis of miR-762 expression. (B) PC-9 cells were stimulated with different doses of IL-6 for $24 \mathrm{~h}$, followed by RT-qPCR analysis of miR-762 expression. (C) PC-9 cells were stimulated with $10 \mathrm{ng} / \mathrm{ml}$ of IL-6 for different durations as indicated, followed by RT-qPCR analysis of miR-762 expression. (D) PC-9 cells were transiently transfected with STAT3 siRNA or Ctrl siRNA. $48 \mathrm{~h}$ later, knockdown of STAT3 in A549 cells was validated using immunoblotting. (H) $48 \mathrm{~h}$ after siRNA treatment,
}

PC-9 cells were stimulated with $10 \mathrm{ng} / \mathrm{ml}$ of IL-6 for $24 \mathrm{~h}$, followed by RTqPCR analysis of miR-762 expression.

Additional file 2: Figure S2. Characterization of $A B R$ mRNA expression in different NSCLC cells using RT-GPCR. The value indicates the relative expression levels of ABR mRNA in the cells (PC-9/PC-9/GR and A549/ A549/GR cells) at different batches of gefitinib resistant induction.

Additional file 3: Figure S3. Identification of a putative STAT3 binding site in the 5'-UTR of pre-miRNA of hsa-miR-762 using the PROmiRNA database.

Additional file 4: Table S1. Details of antibodies used in the current study. Additional file 5: Table S2. 42 candidate genes of miR-762 predicted by Target scan and miRDB programs in the current study.

\section{Abbreviations}

ABR: Active BCR related protein; ANOVA: Analysis of variance; ATCC: American Type Culture Collection; EGFR: Epidermal growth factor receptor; ELISA: Enzyme-linked immunosorbent assay; IL-6: Interleukin-6; LC: Lung cancer; MTT: Methyl thiazolyl tetrazolium; NSCLC: Non-small-cell lung cancer; qPCR: Quantitative polymerase chain reaction; RT: Reverse transcription; SDS-PAGE: Sodium dodecyl sulphate-polyacrylamide gel electrophoresis; TKIs: Tyrosine kinase inhibitors

\section{Acknowledgements}

Not applicable.

\section{Authors' contributions}

PG helped to design the study, performed the experiments and analyzed the data. LC performed the experiments and analyzed the data. XC performed the experiments and analyzed the data. RJ helped to analyze the data. WY designed and supervised the experiments, contributed reagents, analyzed the data, wrote the manuscript and supervised the submission. All authors have read and approved the manuscript, and ensure that this is the case.

\section{Funding}

No funding was obtained for this study.

\section{Availability of data and materials}

All data generated or analyzed during this study are included in this published article [and its supplementary information files].

\section{Ethics approval and consent to participate}

We confirm that none of the cell lines in the current study required ethics approval for their use. The human study was conducted in accordance with the Declaration of Helsinki (2013), and all the protocols involved were approved by the ethics committee review board at Second Affiliated Hospital of Xi'an Medical University (\#XAMU-2007-134-1B). Written informed consent to participate in this study has been obtained from all participants. Mice were bred and housed in accordance with animal welfare rules in a pathogen-free facility. All procedures involved in the animal work were strictly conformed to the Guide for the Care and Use of Laboratory Animals from NIH, and were approved by IACUCs of our hospital (\#XAMU-2007-1341A).

Consent for publication

Not applicable.

\section{Competing interests}

The authors declare that they have no competing interests.

\section{Author details}

${ }^{1}$ Department of Cardiac \& Thoracic Surgery, Second Affiliated Hospital of Xi'an Medical University, Xi'an 710038, People's Republic of China.

Department of Gynecology, Second Affiliated Hospital of Xi'an Medical University, Xi'an 710038, People's Republic of China. ${ }^{3}$ Department of Pathology, Second Affiliated Hospital of Xi'an Medical University, No.167 Fangdong Avenue, Baqiao District, Xi'an 710038, Shaanxi Province, People's Republic of China. 
Received: 19 July 2019 Accepted: 29 November 2019 Published online: 10 December 2019

\section{References}

1. Morgillo F, Della Corte CM, Fasano M, Ciardiello F. Mechanisms of resistance to EGFR-targeted drugs: lung cancer. ESMO Open. 2016;1(3):e000060. https://doi. org/10.1136/esmoopen-2016-000060 esmoopen-2016-000060 [pii].

2. Milovancev A, Stojsic V, Zaric B, Kovacevic T, Sarcev T, Perin B, Zarogoulidis K, Tsirgogianni K, Freitag L, Darwiche K, Tsavlis D, Zissimopoulos A, Stratakos G, Zarogoulidis P. EGFR-TKIs in adjuvant treatment of lung cancer: to give or not to give? Onco Targets Ther. 2015;8:2915-21. https://doi.org/10.2147/ OTT.S91627 ott-8-2915 [pii].

3. Bach DH, Kim D, Bae SY, Kim WK, Hong JY, Lee HJ, Rajasekaran N, Kwon S, Fan Y, Luu TT, Shin YK, Lee J, Lee SK. Targeting Nicotinamide Nmethyltransferase and miR-449a in EGFR-TKI-resistant non-small-cell lung Cancer cells. Mol Ther Nucleic Acids. 2018;11:455-67. doi: S21622531(18)30042-8 [pii]. https://doi.org/10.1016/j.omtn.2018.03.011.

4. Han Z, Zhou X, Li S, Qin Y, Chen Y, Liu H. Inhibition of miR-23a increases the sensitivity of lung cancer stem cells to erlotinib through PTEN/PI3K/Akt pathway. Oncol Rep. 2017;38(5):3064-70. https://doi.org/10.3892/or.2017.5938.

5. Ma W, Kang $Y$, Ning $L$, Tan J, Wang $H$, Ying $Y$. Identification of microRNAs involved in gefitinib resistance of non-small-cell lung cancer through the insulin-like growth factor receptor 1 signaling pathway. Exp Ther Med. 2017; 14(4):2853-62. https://doi.org/10.3892/etm.2017.4847 ETM-0-0-4847 [pii].

6. Lin G, Sheng $H$, Xie H, Zheng Q, Shen Y, Shi G, Ye D. circLPAR1 is a novel biomarker of prognosis for muscle-invasive bladder cancer with invasion and metastasis by miR-762. Oncol Lett. 2019;17(3):3537-47. https://doi.org/ 10.3892/ol.2019.9970 OL-0-0-9970 [pii].

7. Hou R, Yang Z, Wang S, Chu D, Liu Q, Liu J, Jiang L. miR-762 can negatively regulate menin in ovarian cancer. Onco Targets Ther. 2017;10:2127-37. https://doi.org/10.2147/OTT.S127872 ott-10-2127 [pii].

8. Xiang XD, Yu J, Li GF, Xie L, Li H. In vitro study on blocking mTOR signaling pathway in EGFR-TKI resistance NSCLC. Asian Pac J Trop Med. 2014;7(5):394-7. https:/doi.org/10.1016/S1995-7645(14)60063-8.

9. Cao X, Lai S, Hu F, Li G, Wang G, Luo X, Fu X, Hu J. miR-19a contributes to gefitinib resistance and epithelial mesenchymal transition in non-small cell lung cancer cells by targeting c-met. Sci Rep. 2017;7(1):2939. https://doi.org/ 10.1038/s41598-017-01153-0.

10. Ma W, Feng W, Tan J, Xu A, Hu Y, Ning L, Kang Y, Wang L, Zhao Z. miR-497 may enhance the sensitivity of non-small cell lung cancer cells to gefitinib through targeting the insulin-like growth factor-1 receptor. J Thorac Dis. 2018; 10(10):5889-97. https://doi.org/10.21037/jtd.2018.10.40 jtd-10-10-5889 [pii].

11. Zheng X, Xu M, Yao B, Wang C, Jia Y, Liu Q. IL-6/STAT3 axis initiated CAFs via up-regulating TIMP-1 which was attenuated by acetylation of STAT3 induced by PCAF in HCC microenvironment. Cell Signal. 2016;28(9):1314-24. doi: S0898-6568(16)30143-7 [pii]. https://doi.org/10.1016/j.cellsig.2016.06.009.

12. Poholek AC, Jankovic D, Villarino AV, Petermann F, Hettinga A, Shouval DS, Snapper SB, Kaech SM, Brooks SR, Vahedi G, Sher A, Kanno Y, O'Shea JJ. IL10 induces a STAT3-dependent autoregulatory loop in TH2 cells that promotes Blimp-1 restriction of cell expansion via antagonism of STAT5 target genes. Sci Immunol. 2016;1(5).

13. Barnes NA, Stephenson S, Cocco M, Tooze RM, Doody GM. BLIMP-1 and STAT3 counterregulate microRNA-21 during plasma cell differentiation. J Immunol. 2012;189(1):253-60. doi:jimmunol.1101563 [pii]. https://doi.org/10. 4049/jimmunol.1101563.

14. Dong YS, Hou WG, Li Y, Liu DB, Hao GZ, Zhang HF, Li JC, Zhao J, Zhang S, Liang GB, Li W. Unexpected requirement for a binding partner of the syntaxin family in phagocytosis by murine testicular Sertoli cells. Cell Death Differ. 2016;23(5):787-800. doi:cdd2015139 [pii]. https://doi.org/10.1038/cdd. 2015.139.

15. Li W, Wu ZQ, Zhao J, Guo SJ, Li Z, Feng X, Ma L, Zhang JS, Liu XP, Zhang YQ. Transient protection from heat-stress induced apoptotic stimulation by metastasis-associated protein 1 in pachytene spermatocytes. PLoS One. 2011;6(10):e26013. https://doi.org/10.1371/journal.pone.0026013 PONE-D-1113839 [pii].

16. Namasu CY, Katzerke C, Brauer-Hartmann D, Wurm AA, Gerloff D, Hartmann $\mathrm{JU}$, Schwind S, Muller-Tidow C, Hilger N, Fricke S, Christopeit M, Niederwieser D, Behre G. ABR, a novel inducer of transcription factor C/ EBPalpha, contributes to myeloid differentiation and is a favorable prognostic factor in acute myeloid leukemia. Oncotarget. 2017;8(61): 103626-39. https://doi.org/10.18632/oncotarget.22093 22093 [pii].
17. Liu YN, Chang TH, Tsai MF, Wu SG, Tsai TH, Chen HY, Yu SL, Yang JC, Shih JY. IL-8 confers resistance to EGFR inhibitors by inducing stem cell properties in lung cancer. Oncotarget. 2015;6(12):10415-31. https://doi.org/ 10.18632/oncotarget.3389 3389 [pii].

18. Jackman D, Pao W, Riely GJ, Engelman JA, Kris MG, Janne PA, Lynch T, Johnson BE, Miller VA. Clinical definition of acquired resistance to epidermal growth factor receptor tyrosine kinase inhibitors in non-small-cell lung cancer. J Clin Oncol. 2010;28(2):357-60. doi: JCO.2009.24.7049 [pii]. https://doi.org/10.1200/JCO.2009.24.7049.

19. Kwon T, Rho JK, Lee JC, Park YH, Shin HJ, Cho S, Kang YK, Kim BY, Yoon DY, Yu DY. An important role for peroxiredoxin II in survival of A549 lung cancer cells resistant to gefitinib. Exp Mol Med. 2015;47:e165. doi: emm201524 [pii]. https://doi.org/10.1038/emm.2015.24.

20. Kilpinen L, Parmar A, Greco D, Korhonen M, Lehenkari P, Saavalainen P, Laitinen S. Expansion induced microRNA changes in bone marrow mesenchymal stromal cells reveals interplay between immune regulation and cell cycle. Aging (Albany NY). 2016;8(11):2799-813. https://doi.org/10. 18632/aging.101088 101088 [pii].

21. Gao J, Gao L, Li R, Lai Z, Zhang Z, Fan X. Integrated analysis of microRNAmRNA expression in A549 cells infected with influenza a viruses (IAVs) from different host species. Virus Res. 2019;263:34-46. doi: S0168-1702(18)30568-9 [pii]. https://doi.org/10.1016/j.virusres.2018.12.016.

22. Han JJ, Kim DW, Koh J, Keam B, Kim TM, Jeon YK, Lee SH, Chung DH, Heo DS. Change in PD-L1 expression after acquiring resistance to Gefitinib in EGFRmutant non-small-cell lung Cancer. Clin Lung Cancer. 2016;17(4):263-70 e262. doi: S1525-7304(15)00270-3 [pii]. https://doi.org/10.1016/j.cllc.2015.11.006.

23. Fernando RI, Hamilton DH, Dominguez C, David JM, McCampbell KK, Palena C. IL-8 signaling is involved in resistance of lung carcinoma cells to erlotinib. Oncotarget. 2016;7(27):42031-44. https://doi.org/10.18632/oncotarget.9662 9662 [pii].

24. Asirvatham AJ, Magner WJ, Tomasi TB. miRNA regulation of cytokine genes. Cytokine. 2009;45(2):58-69. doi: S1043-4666(08)00797-7 [pii]. https://doi.org/ 10.1016/j.cyto.2008.11.010.

25. Cordeiro AP, da Silva FP, Pieczarka JC, Nagamachi CY, Anselmo NP, Brito JR, Vasconcelos DS, Liehr T, Weise A, de Oliveira EH. Comparative analysis of proliferative and genetic alterations in a primary chordoid meningioma and its recurrence using locus-specific probes and AgNOR. Mol Med Rep. 2009; 2(3):449-54. https://doi.org/10.3892/mmr_00000120.

26. Sim J, Ahn H, Abdul R, Kim H, Yi KJ, Chung YM, Chung MS, Paik SS, Song YS, Jang K. High MicroRNA-370 expression correlates with tumor progression and poor prognosis in breast Cancer. J Breast Cancer. 2015;18(4):323-8. https://doi.org/10.4048/jbc.2015.18.4.323.

27. Hu S, Yuan Y, Song Z, Yan D, Kong X. Expression profiles of microRNAs in drug-resistant non-small cell lung Cancer cell lines using microRNA sequencing. Cell Physiol Biochem. 2018;51(6):2509-22. doi:000495921 [pii]. https://doi.org/10.1159/000495921.

28. Li Y, Huang R, Wang L, Hao J, Zhang Q, Ling R, Yun J. microRNA-762 promotes breast cancer cell proliferation and invasion by targeting IRF7 expression. Cell Prolif. 2015:48(6):643-9. https://doi.org/10.1111/cpr.12223.

29. Yang Z, Wang L. Regulation of microRNA expression and function by nuclear receptor signaling. Cell Biosci. 2011;1(1):31. doi:2045-3701-1-31 [pii]. https://doi.org/10.1186/2045-3701-1-31.

30. Wang J, Wang Y, Zheng C, Hou K, Zhang T, Qu X, Liu Y, Kang J, Hu X, Che $X$. Tyrosine kinase inhibitor-induced IL-6/STAT3 activation decreases sensitivity of EGFR-mutant non-small cell lung cancer to icotinib. Cell Biol Int. 2018;42(10):1292-9. https://doi.org/10.1002/cbin.11000.

31. Tamura T, Kato Y, Ohashi K, Ninomiya K, Makimoto G, Gotoda H, Kubo T, Ichihara E, Tanaka T, Ichimura K, Maeda Y, Hotta K, Kiura K. Potential influence of interleukin- 6 on the therapeutic effect of gefitinib in patients with advanced non-small cell lung cancer harbouring EGFR mutations. Biochem Biophys Res Commun. 2018;495(1):360-7. doi: S0006291X(17)32163-0 [pii]. https://doi.org/10.1016/j.bbrc.2017.10.175.

32. Yao Q, Wang X, He W, Song Z, Wang B, Zhang J, Qin Q. Circulating microRNA-144-3p and miR-762 are novel biomarkers of Graves' disease. Endocrine. 2019. https://doi.org/10.1007/s12020-019-01884-2.

33. McDonald JD, Daneshvar L, Willert JR, Matsumura K, Waldman F, Cogen PH. Physical mapping of chromosome 17p13.3 in the region of a putative tumor suppressor gene important in medulloblastoma. Genomics. 1994;23(1):229-32. doi: S0888-7543(84)71481-9 [pii]. https://doi.org/10.1006/geno.1994.1481.

34. Liscia DS, Morizio R, Venesio T, Palenzona C, Donadio M, Callahan R. Prognostic significance of loss of heterozygosity at loci on chromosome 
17p13.3-ter in sporadic breast cancer is evidence for a putative tumour suppressor gene. Br J Cancer. 1999;80(5-6):821-6. https://doi.org/10.1038/sj. bjc.6690427.

35. Willert JR, Daneshvar L, Sheffield VC, Cogen PH. Deletion of chromosome arm 17p DNA sequences in pediatric high-grade and juvenile pilocytic astrocytomas. Genes Chromosom Cancer. 1995;12(3):165-72.

36. Yu M, Gong D, Lim M, Arutyunyan A, Groffen J, Heisterkamp N. Lack of ber and abr promotes hypoxia-induced pulmonary hypertension in mice. PLoS One. 2012;7(11):e49756. https://doi.org/10.1371/journal.pone.0049756 PONED-11-25473 [pii].

37. Chen Z, Fillmore CM, Hammerman PS, Kim CF, Wong KK. Non-small-cell lung cancers: a heterogeneous set of diseases. Nat Rev Cancer. 2014;14(8): 535-46. doi:nrc3775 [pii]. https://doi.org/10.1038/nrc3775.

\section{Publisher's Note}

Springer Nature remains neutral with regard to jurisdictional claims in published maps and institutional affiliations.

Ready to submit your research? Choose BMC and benefit from:

- fast, convenient online submission

- thorough peer review by experienced researchers in your field

- rapid publication on acceptance

- support for research data, including large and complex data types

- gold Open Access which fosters wider collaboration and increased citations

- maximum visibility for your research: over $100 \mathrm{M}$ website views per year

At BMC, research is always in progress.

Learn more biomedcentral.com/submissions 